\title{
First report of Strawberry necrotic shock virus infecting strawberry (Fragaria vesca) from Australia
}

\author{
Murray Sharman • Fiona Constable • Ruvinda Perera • \\ John E. Thomas
}

Received: 20 April 2011 / Accepted: 13 June 2011 /Published online: 8 July 2011

(C) Australasian Plant Pathology Society Inc. 2011

\begin{abstract}
The complete coat protein gene sequence is described for three isolates of Strawberry necrotic shock virus (SNSV) isolated from strawberry (Fragaria vesca) from Australia. Sequences for these isolates were found to have close identity to SNSV isolates from North America. This is the first report of SNSV from Australia.
\end{abstract}

Keywords Ilarvirus

In Australia, the ilarvirus Tobacco streak virus (TSV) was first described from tobacco in the early 1970s (Greber 1971) and has been mostly studied in south-eastern Queensland. An ilarvirus isolated from the M9 clone of strawberry (Frageria vesca) cv. Redlands Crimson, designated TSV-S, was first described by Greber (1979) and Klose et al. (1996) suggested that it may have originated from imported North American strawberry clones. Sdoodee (1989) demonstrated serological and host range differences between three strains of "TSV" found in Australia. One notable difference being that while strains TSV-Ag and TSV-A both produced dentate leaves in systemic infections of Nicotiana tabacum cv. Turkish (Greber 1971; Sdoodee

\footnotetext{
M. Sharman $(\bowtie)$

Department of Employment, Economic Development and Innovation, Ecosciences Precinct,

GPO Box 46, Brisbane, Queensland 4001, Australia

e-mail: murray.sharman@qld.gov.au

F. Constable $\cdot$ R. Perera

Department of Primary Industries,

Knoxfield, Victoria 3156, Australia

J. E. Thomas

The University of Queensland, Queensland Alliance for Agriculture and Food Innovation, Ecosciences Precinct, GPO Box 46, Brisbane, Queensland 4001, Australia
}

1989), TSV-S failed to do so (Greber 1979). Klose et al. (1996) also demonstrated different rates of transmission efficiency between the three strains using different thrips species as vectors.

TSV-S, from Dr Ratana Sdoodee (Sdoodee 1989), was deposited in the Queensland Department of Employment, Economic Development and Innovation plant virus collection as isolate-840, and stored as desiccated leaf tissue in the indicator host Nicotiana tabacum cv. Xanthi. Isolates CVIC21 and CVIC22 were sampled from two unknown strawberry cultivars being grown as reference isolates of what was thought to be TSV at the Victoria Department of Primary Industries, Knoxfield laboratories. The origin of these reference plants is unclear but they are likely to have been subsamples of the original M9 clone from Queensland.

For isolate-840, total RNA was extracted from desiccated leaf tissue using a BioSprint 15 workstation (Qiagen) with a BioSprint 15 Plant DNA kit (Qiagen) as per the manufacturer's instructions, but without the use of RNase A. For isolates CVIC21 and CVIC22, total RNA was extracted using the RNeasy Plant Mini kit (Qiagen) with a modified lysis buffer (MacKenzie et al. 1997).

For PCR amplification of the complete coat protein gene from the Victorian isolates CVIC21 and CVIC22, primer SNSV CPbeg F (Tzanetakis et al. 2004) was used with primer TSVcpR4 (5' CGG ATG CGY GGY ARC TAT GCA $\mathrm{T} 3^{\prime}$ ) which was designed to a conserved region of previously published sequences for TSV, Strawberry necrotic shock virus (SNSV) and Parietaria mottle virus (PMoV) (GenBank accessions NC_003845, AY363228 and NC_005854, respectively). The SuperScript One-Step RTPCR System (Invitrogen) was used as per the manufacturer's instructions except the total reaction volume was $25 \mu \mathrm{l}$. A product of $930 \mathrm{bp}$ was amplified from each isolate. 


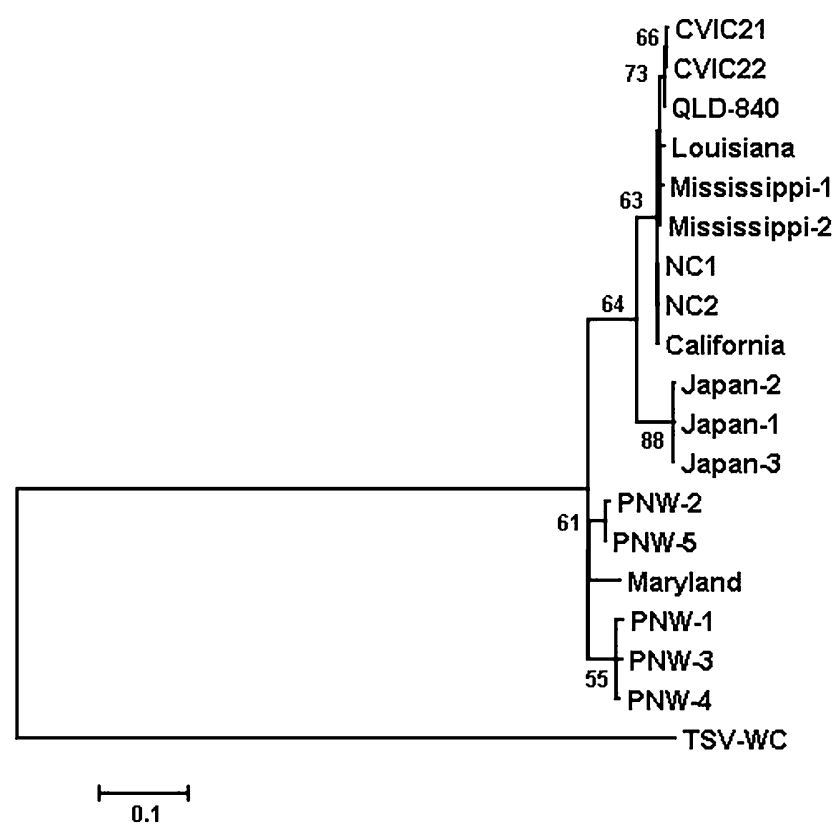

Fig. 1 Maximum Likelihood dendrogram, based on the Kimura 2parameter model, illustrating coat protein gene nucleotide sequence relationships of SNSV isolates. A discrete Gamma distribution was used to model evolutionary rate differences among sites. Horizontal distances are proportional to nucleotide substitutions per site, and the dendrogram was bootstrapped 500 times with branch values greater than $50 \%$ indicated. The scale bar represents the number of nucleotide substitutions per site. TSV was used as an out-group to root the phylogenetic tree. Abbreviations and GenBank accession numbers used are: CVIC21 (JF781587), CVIC22 (JF781588), QLD-840 (JF781586), Mississippi-1-2 (AY363232, AY363233), Louisiana (AY363234), NC1-2 (North Carolina; AY363235, AY363237), California (AY363236), Japan1-3 (AY363229, AY363230, AY363231), PNW-1-5 (Pacific North West, USA; AY363238, AY363239, AY363240, AY363241, AY363242), Maryland (AY363228) and TSVWC (NC_003845)

These products were cloned using the pGEM-T Easy Vector system (Promega) as per the manufacturer's instructions. Three clones each of isolates CVIC21 and CVIC22 were sequenced in both directions and after removal of primer sites, the $883 \mathrm{nt}$ consensus sequences were lodged with GenBank (accessions JF781587 and JF781588).

To obtain the complete coat protein gene of Queensland isolate-840, SuperScript III reverse transcriptase (Invitrogen) was used to prepare cDNA with primer TSVcpR4 as per the manufacturer's instructions followed by PCR with primers TSVmpF1 (Sharman et al. 2009) and TSVcpR4 at an annealing temperature of $57^{\circ} \mathrm{C}$. A product of $1273 \mathrm{bp}$ was amplified. PCR products were either electrophoresed using an E-gel CloneWell $0.8 \%$ SYBR Safe gel (Invitrogen) on an iBase (Ethrong Biotechnologies Ltd) as per the manufacturers' instructions and extracted in water, or purified from a $0.5 \times$ TBE agarose gel using a Qiaquick PCR purification kit (Qiagen). PCR products for isolate-840 were directly sequenced in both directions with an Applied Biosystems
Inc. automated sequencing system at the Australian Genome Research Facility, Brisbane, and after removal of primer sites, the 1229 nt sequence was lodged with GenBank (JF781586). Sequence alignments, dendrograms and genetic distances were produced using $M E G A$ version 5 (Tamura et al. 2011). Nucleotide identity searches of the GenBank database were done using the Basic Local Alignment Search Tool (BLAST; Altschul et al. 1990).

The nucleotide sequences of isolate-840, CVIC21 and CVIC22 were $>99.5 \%$ identical to each other over a $883 \mathrm{nt}$ overlap and $>99 \%$ identical over the 222 amino acid overlap of the putative coat protein. The next two closest nucleotide sequence identities with Queensland isolate-840, from GenBank by BLAST, were with isolates of SNSV; $99 \%$ over a $669 \mathrm{nt}$ overlap with an isolate from Mississippi, United States of America (USA; AY363233), and then 92\% over a $1227 \mathrm{nt}$ overlap with an isolate from Maryland, USA (AY363228). When compared with other published putative coat protein gene sequences (Fig. 1) the Australian isolates of SNSV are most closely related to isolates from Mississippi and Louisiana, USA.

This is the first report of SNSV from Australia and confirms that Queensland isolate-840, which was previously referred to as a strain of Tobacco streak virus, TSV-S (Greber 1979; Klose et al. 1996; Sdoodee 1989), is SNSV. The close nucleotide identity of the Australian SNSV isolates with isolates from Mississippi, USA, is in agreement with the suggestion by Klose et al. (1996) that strain TSV-S may have originated from North American strawberry plants introduced into Australia. It appears likely that the Victorian isolates of SNSV described here represent sub-samples of the original Queensland isolate-840. However, SNSV has not been found to naturally infect other host plants in Australia.

Acknowledgements This work was funded by the Grains Research and Development Corporation, the Cotton Research and Development Corporation of Australia, the Queensland Department of Employment, Economic Development and Innovation, and the Victorian Department of Primary Industries.

\section{References}

Altschul SF, Gish W, Miller W, Myers EW, Lipman DJ (1990) Basic local alignment search tool. J Mol Biol 215:403-410

Greber RS (1971) Some characteristics of tobacco streak virus isolates from Queensland. Queensl J Agr Anim Sci 28:105-114

Greber RS (1979) Virus diseases of Queensland strawberries and the epidemiological effects of the strawberry runner approval scheme. Queensl J Agr Anim Sci 36:93-103

Klose MJ, Sdoodee R, Teakle DS, Milne JR, Greber RS, Walter GH (1996) Transmission of three strains of tobacco streak ilarvirus by different thrips species using virus-infected pollen. J Phytopathol 144:281-284

MacKenzie DJ, McLean MA, Mukerji S, Green M (1997) Improved RNA extraction from woody plants for the detection of viral 
pathogens by reverse transcription-polymerase chain reaction. Plant Disease 81:222-226

Sdoodee R (1989) Biological and physicochemical properties of Tobacco streak virus. $\mathrm{PhD}$ thesis, University of Queensland

Sharman M, Persley DM, Thomas JE (2009) Distribution in Australia and seed transmission of Tobacco streak virus in Parthenium hysterophorus. Plant Disease 93:708-712
Tamura K, Peterson D, Peterson N, Stecher G, Nei M, Kumar S (2011) MEGA5: molecular evolutionary genetics analysis using maximum likelihood, evolutionary distance, and maximum parsimony methods. Mol Biol Evol (In press)

Tzanetakis IE, Mackey IC, Martin RR (2004) Strawberry necrotic shock virus is a distinct virus and not a strain of Tobacco streak virus. Arch Virol 149:2001-2011 